${ }^{1}$ En esta línea también se inserta el proyecto de $\mathrm{PH} 60$, monográfico dedicado integramente a Itinerarios y Rutas Culturales. Este número de Debate e Investigación, coordinado por Antonio Campesino, catedrático de la Universidad de Extremadura, saldrá publicado en octubre de 2006. En el próximo número de $\mathrm{PH}$ se avanzarán posibles cuestiones para reflexionar sobre el tema en la sección Opinión del Lector.

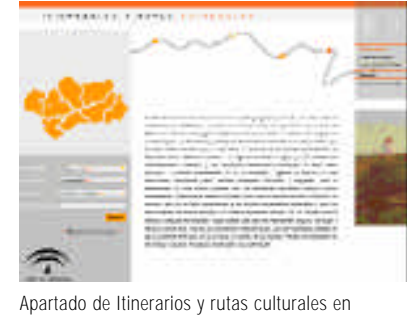

Apartado de Itinerarios y rutas culturales en www.juntadeandalucia.es/ cultura/ iaph Página inicial

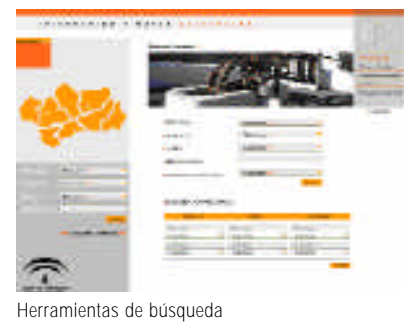

\title{
Itinerarios y rutas culturales en la web del IAPH
}

Andalucía ha sido históricamente una encrucijada geográfica y cultural, un enlace entre el Mediterráneo y el Atlántico, un punto de encuentro entre Europa, América y el norte de África. En ella han convergido múltiples y diversos pueblos o culturas que llegaron a nuestra región, se asentaron y produjeron intercambios incesantes de ida y vuelta que perduran hasta nuestros días. La sucesión de todas estas influencias culturales combinadas con las características geográficas tan diversas del territorio andaluz han generado una riqueza de respuestas culturales y un dinamismo que se manifiestan a través de nuestro rico y variado patrimonio cultural en sus aspectos materiales 0 inmateriales.

Ante esta riqueza y variedad del patrimonio cultural andaluz y la combinación con su diversidad territorial, en el Centro de Documentación del IAPH planteamos a inicios de 2004 el Proyecto de Itinerarios y Rutas Culturales ${ }^{1}$, que acaba de salir a la luz a través del Portal Web del IAPH y ser presentado públicamente recientemente por la Consejera de Cultura, Rosario Torres Ruiz.

Con este proyecto se pretende ofrecer a diferentes tipos de usuarios (profesionales del patrimonio, población local, estudiantes, investigadores, turistas) múltiples recorridos por la enorme riqueza del patrimonio cultural de Andalucía. De forma indirecta, pretendemos contribuir a relacionar la información patrimonial de la que disponemos con las infraestructuras asentadas en el territorio necesarias para una difusión coherente y duradera del patrimonio cultural andaluz a través del uso sostenible del turismo cultural.

En esta primera etapa, nuestros objetivos básicos son:

$>$ Identificar Itinerarios Culturales ofreciendo las experiencias actuales y futuras dentro de la línea conceptual marcada por el Comité Internacional de Itinerarios Culturales (CIIC) del ICOMOS.

$>$ Documentar y difundir Rutas Culturales. Hemos centrado nuestros esfuerzos en recopilar rutas culturales elaboradas, en algunos casos por el propio $\mathrm{IAPH}$, pero fundamentalmente por otras entidades o instituciones, ya sea desde la óptica patrimonial (Consejería de Cultura) 0 desde otras perspectivas, pero cuyas actuaciones afectan siempre, directa 0 indirectamente, al Patrimonio Cultural (Consejería de Turismo, Diputaciones, Ayuntamientos, Grupos de Desarrollo Rural...).

$>$ Elaborar Rutas Culturales con una metodología integradora e interdisciplinar, con el rigor y la capacidad comunicativa y divulgativa que aporten los enfoques disciplinarios implicados (antropología, arquitectura, historia del arte, arqueología). En principio pretendemos optimizar las actuaciones que desde el IAPH 0 desde otros servicios 0 entidades de la Consejería de Cultura se hayan realizado en este sentido, ya sea por la información contenida en nuestras bases de datos, 0 a través de productos de difusión que sean susceptibles de presentarse en forma de rutas culturales. En segundo lugar, nuestra apuesta más ambiciosa va dirigida a abordar la elaboración de rutas culturales por Andalucía para responder a una necesidad crucial de dar una información de calidad alternativa, de contenido patrimonial multidimensional y no banalizado, que ponga énfasis en el patrimonio cultural en su doble dimensión material e inmaterial, en sus valores históricos y sociales como referente identitario y, en Andalucía, como una realidad diversa y multicultural.

Por ello, hemos intentado aunar en una sola herramienta la diversa información que hemos estimado interesante para alcanzar estos primeros objetivos, de modo que la estructura del contenido de la página sería la que sigue:

$>$ Con Itinerario Cultural accederíamos a bibliografía, cartas internacionales y experiencias en el ámbito de actuación marcado por el CIIC del ICOMOS, entendiendo por "Itinerario Cultural": Toda vía de comunicación terrestre, acuática o de otro tipo, físicamente determinada y caracterizada por poseer su propia y específica dinámica y funcionalidad histórica (un Itinerario Cultural debe reunir las siguientes características: a) ser resultado y reflejo de movimientos interactivos de personas, así como de intercambios multidimensionales, continuos y recíprocos de bienes, ideas, conocimientos y valores dentro de un país o entre varios países y regiones a lo largo de considerables períodos de tiempo; b) haber generado una fecundación múltiple y recíproca de las culturas en el espacio y en el tiempo que se manifiesta tanto en su patrimonio tangible como intangible).

$>$ A través de Rutas Culturales, entendidas como recorridos espaciales de contenido patrimonial que siven como ejes de difusión de la relación cultura-territorio-identidad en Andalucía, resultado de un proceso histórico compartido y dialéctico, presentamos nuestros objetivos de documentar y, al mismo tiempo, elaborar rutas, señalando los criterios metodológicos, temáticos y territoriales que las orientarán. Para ello pretendemos aplicar una metodología que tenga en cuenta las diferentes disciplinas y enfoques sobre el patrimonio cultural, la relación del patrimonio con el entorno y la dimensión identitaria y multicultural del mismo, así como la integración del valor material e inmaterial de todos los bienes patrimoniales. A priori no descartamos ninguna asociación temática o territorial pero como zona preferente de actuación dirigiremos nuestras miras más a las ciudades intermedias y centros rurales andaluces, ya sean interiores, de costa o de montaña, que a potenciar las 

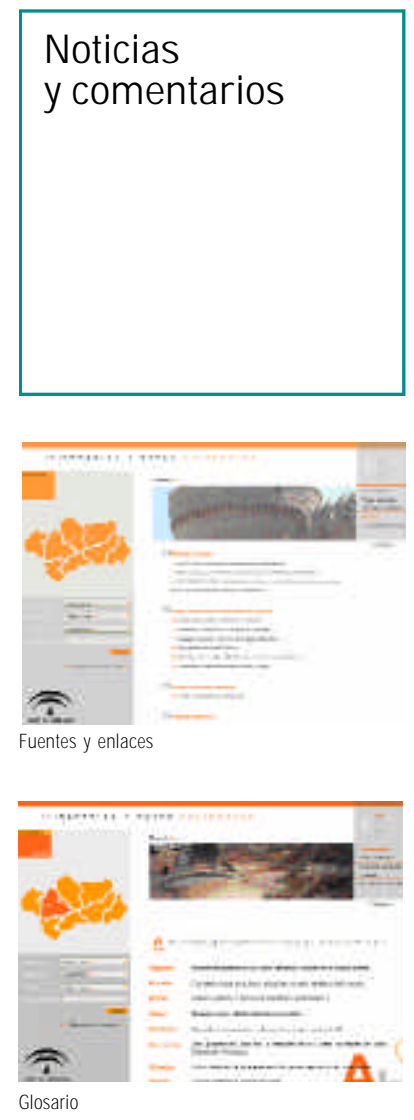

rutas entre los grandes centros regionales, que, sin duda, albergan un patrimonio importantísimo pero que gozan ya de un mayor grado de conocimiento, han sido más documentados, intervenidos y forman parte de destinos turísticos consolidados históricamente. Trataremos también de identificar ejes temáticos capaces de transmitir de forma integral y completa toda la complejidad del patrimonio cultural de Andalucía. Las categorías temáticas empleadas responden a criterios diversos. En algunos casos son conceptos muy amplios que albergan todo tipo de elementos culturales como por ejemplo la categoría "patrimonio industrial" (inmuebles, muebles, actividades...) y, en otros casos, son más restrictivas (arquitectura civil, religiosa o defensiva). Ello se debe a la propia idiosincrasia de las rutas documentadas por el momento y a las características de las mismas, referidas en su mayoría a las tipologías funcionales y categorías patrimoniales que siguen el modelo decimonónico del Patrimonio cultural, relacionado con las élites sociales con mayor poder político-religioso o económico. No obstante, las categorías temáticas que emplearemos para nuestras rutas deberán ampliarse en la medida que elaboremos rutas desde una perspectiva interdisciplinar y aplicando los criterios metodológicos antes expuestos.

$>$ Herramienta de búsqueda (mapa y texto) para la consulta y recuperación de Rutas e Itinerarios Culturales en Andalucía. A través de la herramienta de Búsqueda del Producto Itinerarios y Rutas Culturales se podrán consultar tanto las rutas culturales que hemos recopilado como las rutas creadas por el Centro de Documentación del IAPH. También se podrán recuperar los Itinerarios Culturales que vayamos identificando. Los criterios de búsqueda son básicamente de tipo geográfico 0 temático. Es decir, podemos buscar todas las rutas de una determinada categoría temática (una 0 varias) 0 bien las rutas que se encuentren en una determinada zona geográfica (mapa de Andalucía por provincias) o que pasen por una 0 varias provincias o municipios (campos de texto). En la Búsqueda avanzada podremos combinar ambos criterios además de algunas otras características de las rutas. Más adelante, conforme vayan aumentando las rutas, se irán aumentando los criterios de búsqueda geográfica y temática, incluyendo entre otras, las divisiones territoriales supramunicipales del POTA, los espacios protegidos, comarcas, etc.

$>$ Fuentes y Enlaces. Listado de fuentes de información y enlaces a documentos y/ o páginas Web con información relacionada y de interés.

$>$ Mi Cuaderno de Viaje. Buzón de correos abierto a las aportaciones de los usuarios (asociaciones, población local o viajeros) que quieran proponer una posible ruta por su propio territorio y su patrimonio, o una experiencia de viaje, así como otro tipo de aportación que pueda servir para enriquecer esta experiencia.

$>$ Glosario para la definición de términos relacionados y categorías temáticas empleadas
En definitiva y para concluir, con este producto pretendemos difundir el rico y variado patrimonio cultural de Andalucía a través de la identificación de Itinerarios Culturales, y la documentación y elaboración de Rutas Culturales. Éstos serán el reflejo del dinamismo cultural e histórico de Andalucía, a través de diversos recorridos que nos muestren los bienes de interés arqueológico, etnológico 0 arquitectónico; la importante arquitectura civil, religiosa y defensiva; los ingenios hidráulicos y obras públicas; la rica y variada arquitectura "popular" o vernácula que ha producido formas tan diversas y originales de adaptarse a las necesidades del entorno (mediante edificios para la vivienda, actividades productivas o espacios de sociabilidad); y las múltiples expresiones artísticas, que son hoy patrimonio de Andalucía. También son reflejo de este dinamismo los paisajes culturales generados, los sistemas de producción agropecuaria e industrial, así como en el rico y extenso patrimonio vinculado con la actividad marítima en sus diferentes facetas, sumergidas o emergidas, y que son hoy testigo de la relación del hombre con el mar (arquitectura defensiva, actividad pesquera, actividad salinera, la construcción naval, así como en la rica circulación comercial y cultural de sus ciudades y puertos). Y, no por último, menos importante, dicha efervescencia cultural se deja ver en todo su complejo sistema de ciudades, desde los centros regionales, pasando por las cruciales y significativas ciudades intermedias, patrimonio cultural y territorial de Andalucía, hasta sus centros rurales o pequeños asentamientos; así como en la configuración territorial de sus tan interesantes comarcas histórico culturales, verdaderos ecosistemas ecológicos culturales que explican la diversidad de estas manifestaciones culturales de Andalucía.

Por último, intentaremos reflejar las diferentes acciones relacionadas con Rutas Culturales y centradas en la difusión del Patrimonio Cultural dando al usuario la posibilidad de aunar las diferentes propuestas en un solo instrumento, y por otro lado, analizar el contenido que se está ofreciendo del patrimonio cultural como objeto de reclamo turísti$\mathrm{CO}$, atendiendo a los aspectos positivos o negativos que esto pueda reportar al patrimonio cultural de Andalucía. En definitiva, ser un punto de encuentro para la reflexión, el debate y la investigación sobre temas tan importantes como la cultura y el turismo en Andalucía, sus asociaciones, virtudes 0 desequilibrios.

Gema Carrera Díaz

Proyecto Itinerarios y Rutas Culturales

Centro de Documentación del IAPH 